\title{
Study of Upper Pharyngeal Airway Dimension in Young Adults Visiting Orthodontic Department of a Dental College: A Descriptive Cross- sectional Study
}

\author{
Resina Pradhan, ${ }^{1}$ Anjana Rajbhandari, ${ }^{1}$ Manju Bajracharya, ${ }^{1}$ Pushkar Manandhar,' Surendra Maharjan, \\ Bashu Dev Pant, \\ 'Department of Orthodontics, People's Dental College and Hospital, Kathmandu, Nepal.
}

\section{ABSTRACT}

Introduction: Orthodontic treatment may affect the size and position of oropharyngeal structures altering the airway dimension. Airway dimension is considered as one of the parameter of orthodontic diagnosis and treatment planning. Narrow airway passage is associated with sleep disordered breathing. This aims to study about the measurement of upper pharyngeal airway dimension of young Nepalese adults visiting orthodontic department of a dental college.

Methods: This descriptive cross-sectional study conducted at Department of Orthodontics, People's Dental College and Hospital, Kathmandu. Data was collected from $8^{\text {th }}$ December 2020 to $28^{\text {th }}$ February 2021. Ethical clearance (Reference number. 1, CH100 06, 2077/2076) was taken from Institutional Review Committee of Peoples Dental College and Hospital, Kathmandu, Nepal. Convenient Sampling technique was done. Data was collected and analysis was done using Statistical Package of Social Sciences 16.

Results: Mean upper pharyngeal airway dimension was $11.40 \pm 1.84 \mathrm{~mm}$ and $11.68 \pm 1.96 \mathrm{~mm}$ for male and female respectively. Upper pharyngeal airway dimension was found to be almost similar for male and female.

Conclusions: Gender diversity regarding upper pharyngeal airway dimesnion was not observed in this study while other studies also revealed similarities in upper pharyngeal airway dimension between male and female, inspite of larger craniofacial dimension in males than females.

Keywords: airway; hyoid bone position; tongue dimension.

\section{INTRODUCTION}

Positional changes of mandible during orthodontic treatment may alter tongue and hyoid bone position affecting pharyngeal airway dimension. ${ }^{1}$ Reduced airway passage is detrimental and has been associated with abnormal growth of craniofacial structures and may be associated with sleep disordered breathing. ${ }^{2}$

Widening the narrow airway passage with mandibular advancement allows anterior positioning of hyoid bone and provides normal breathing and normal growth of craniofacial structures. ${ }^{3}$ There has been various studies to measure upper pharyngeal airway in individual with normal craniofacial structures as well as abnormal facial pattern. ${ }^{4}$

As stated in literatures airway dimension, tongue size and hyoid bone position are highly reproducible in lateral cephalogram. ${ }^{5}$ The objective of this study is to measure upper pharyngeal airway dimension in young Nepalese adults visting orthodontic department of a dental college of Kathmandu.

\section{METHODS}

The study design was descriptive cross-sectional study conducted at Department of Orthodontics, Peoples Dental College and Hospital, Kathmandu from $8^{\text {th }}$ December 2020 to $28^{\text {th }}$ February 2021. Ethical clearance (Ref. no. 1, CH100 06, 2077/2076) was taken

Correspondence: Dr. Resina Pradhan, Department of Orthodontics, People's Dental College and Hospital, Kathmandu, Nepal. Email: resina.shrestha@gmail.com, Phone: +977. 9851009002 . 
from Institutional Review Committee of People's Dental College and Hospital, Kathmandu, Nepal. Lateral cephalograms of Nepalese young adults aged 18-27 years visiting orthodontic department, seeking orthodontic treatment were selected based on inclusion and exclusion criterion (Angles class I molar and canine relation with normal overjet and overbite, skeletal class I with normal growth pattern were included and mouth breathing habit, craniofacial abnormalities and orthodontic treatment were excluded). Written and signed consent was taken prior to pre-treatment record collection. Pilot study was performed in thirty lateral cephalograms to know standard deviation and error. Then with the adjusted error, sample size was determined to be 114 .

$$
\begin{aligned}
N & =\left(z^{2} \times \sigma^{2}\right) / \mathrm{e}^{2} \\
& =\left((1.96)^{2} \times(0.6)^{2}\right) /(0.11)^{2} \\
& =114
\end{aligned}
$$

Where,

$$
\begin{aligned}
& Z=1.96 \text { at } 95 \% \text { Confidence Interval } \\
& \sigma=0.6 \text { from pilot study } \\
& e=\text { margin of error }, 0.11
\end{aligned}
$$

The calculated sample size was 114 . Increase in $10 \%$ sample size $(114+11=125)$ was to mitigate error that may arise due to difficulty in land mark localisation.

Lateral cephalograms was obtained using Sirona Orthophos SL. exposed at $73 \mathrm{KV}$ - $15 \mathrm{~mA}$ to $84 \mathrm{KV}$ $13 \mathrm{~mA}$ for all patients, with patient in natural head position for reproducibility of landmarks, maximum intercuspation and light lip contact. The patients were asked not to swallow or move tongue or head during the exposure.

For pre-testing thirty lateral cephalograms, which were not included in the study sample, were collected and study variables were analysed prior to the research study. In the selected upper pharyngeal width 125 samples name and sex in the lateral cephalograms were blinded. Using the tracing paper, view box and micro lead $3 \mathrm{H}$ pencils fifteen randomly selected lateral cephalograms were traced and landmarks were localized. These lateral cephalograms were relocalised by other investigators to check accuracy in landmark localization. This was followed by tracing, landmark localization and measurement of the parameters of the research study manually by the principal investigator. Twenty five lateral cephalograms was drawn randomly and the parameters were remeasured in one week interval to test intraobserver variation in landmark measurement. All the collected information was recorded in proforma.

As a research parameter, upper pharyngeal airway dimesnsion was measured from a point on anterior half of posterior outline of the soft palate to the closest point on the Posterior Pharyngeal Wall. Lower Pharyngeal Width was measured from the point of intersection of the posterior border of the tongue and the inferior border of the mandible to the closest point on the Posterior Pharyngeal Wall. Hyoid Bone position measured as perpendicular distance from Superior Anterior Point in Hyoid Bone to Mandibular Plane. Tongue Length from base of Epiglottis to Tip of the Tongue. Tongue Height was measured as perpendicular distance from maximum height of dorsum of tongue to Tongue Length. ${ }^{1}$ Measuring scale had $0.5 \mathrm{~mm}$ of accuracy for precision in measurement.

Data was fed in Microsoft Excel. Descriptive statistics was drawn using SPSS 16 (Statistical Package of Social Sciences). Frequency distribution of the variables checked in histogram for normal distribution.

Error in measurement was evaluated finding Dahlberg error (1940) to know the impact of the error on final result.

$D=\sqrt{\sum_{i=1}^{N} \frac{d_{i}^{2}}{2 N}}$

Where $d_{1}$ is the difference between the first and second measure, $\mathrm{N}$ is the remeasured sample size 25 . Dahlberg error for different parameters lied between 0.1 to $0.5 \mathrm{~mm}$ with minimum deviation for hyoid bone position and largest deviation for tongue length. ${ }^{6}$ Systematic error in this study has been reduced by using lateral cephalogram from same X-ray machine by single observer. To minimize the systemic error, the data presented in the study is the original data without adjustment for the radiographic magnification of $13 \%$.

\section{RESULTS}

Mean and standard deviation of upper pharyngeal

\begin{tabular}{|l|c|}
\hline \multicolumn{2}{|l|}{$\begin{array}{l}\text { Table 1. Variations in Upper Pharyngeal Airway } \\
\text { Dimension. }\end{array}$} \\
\hline & $\begin{array}{l}\text { Upper } \\
\text { Dimension (Mean } \pm \text { S.D) (mm) }\end{array}$ \\
\hline Female & $11.68 \pm 1.96$ \\
\hline Male & $11.40 \pm 1.84$ \\
\hline Total & $\mathbf{1 1 . 5} \pm \mathbf{1 . 9 4}$ \\
\hline
\end{tabular}


Pradhan et al. Study of Upper Pharyngeal Airway Dimension in Young Adults Visiting Orthodontic Department...

\begin{tabular}{|l|c|c|c|}
\hline Table 2. Parameters Related to Upper Pharyngeal Airway Dimension. \\
\hline Abbreviations & Total (Mean \pm S.D) $(\mathbf{m m})$ & Male (Mean \pm S.D) $(\mathbf{m m})$ & Female (Mean \pm S.D) $(\mathbf{m m})$ \\
\hline Lower Pharyngeal Width & $10.27 \pm 2.71$ & $11.23 \pm 2.45$ & $9.38 \pm 2.65$ \\
\hline Tongue Height & $34.73 \pm 2.84$ & $35.82 \pm 2.95$ & $33.72 \pm 2.34$ \\
\hline Tongue Length & $72.50 \pm 5.02$ & $74.62 \pm 5.10$ & $70.54 \pm 4.10$ \\
\hline Hyoid Bone position & $9.99 \pm 4.42$ & $10.93 \pm 4.14$ & $9.12 \pm 4.53$ \\
\hline
\end{tabular}

The frequency of quantitative data of five different variables of airway, tongue dimension and hyoid bone position showed frequency distribution graph (Figure 1) with normal distribution approximately.

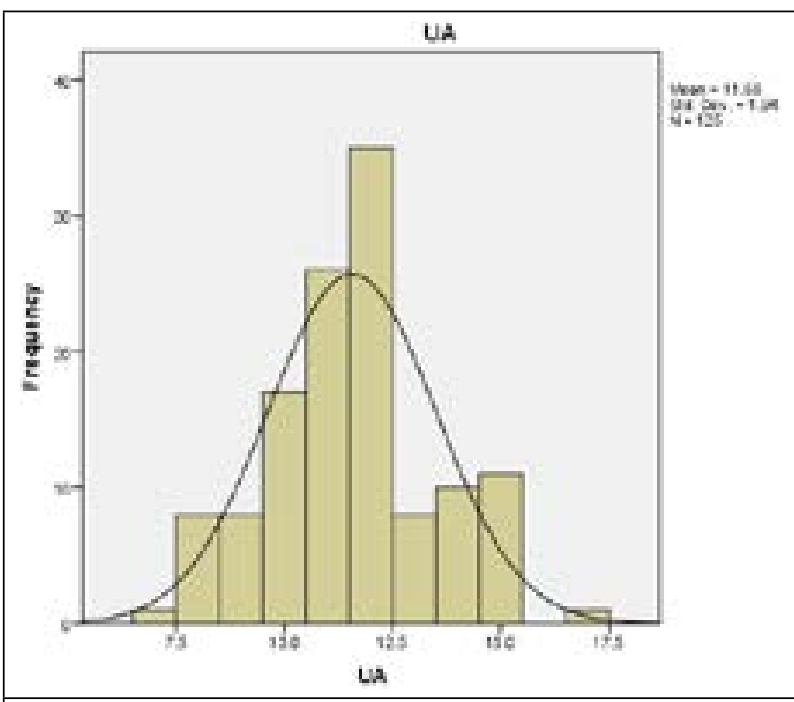

Figure 1. Histogram showing Normal Distribution for Upper Pharyngeal Airway Dimension.

Mean age of participants involved in study, both males and females (Table 3).

\begin{tabular}{|l|l|l|l|}
\hline \multicolumn{3}{|l|}{ Table 3. Demographic Data. } \\
\hline \multirow{4}{*}{ Age } & Sex & $\mathbf{n}$ & Mean \pm S.D (yrs) \\
\cline { 2 - 4 } & Male & 60 & $20.75 \pm 2.67$ \\
\cline { 2 - 4 } & Female & 65 & $20.05 \pm 2.25$ \\
\cline { 2 - 4 } & Total & 125 & $20.38 \pm 2.47$ \\
\hline
\end{tabular}

\section{DISCUSSION}

Findings of our study, the mean upper pharyngeal airway dimension was $11.56 \pm 1.94 \mathrm{~mm}$, lower airway dimension was $10.27 \pm 2.71 \mathrm{~mm}$, tongue height was $34.73 \pm 2.84 \mathrm{~mm}$, tongue length was $72.50 \pm 5.02 \mathrm{~mm}$ and the position of hyoid bone was $9.99 \pm 4.42 \mathrm{~mm}$.

The aim of orthodontic treatment is to achieve maximum functional efficiency beside esthetic harmony. Like mastication, breathing is also one of the crucial functions performed by the craniofacial structure. Narrow airway passage leads to altered breathing and abnormal growth of functional components resulting abnormal morphologic pattern. Hence this study was performed with the objective of measuring airway dimension and to know the measure and the position of oropharyngeal structures, the tongue and hyoid bone. Therefore, while achieving esthetical harmony and masticatory functional efficiency, breathing has to be given equal importance.

Normal functional components will have normal functioning and normal morphological pattern of airway and tongue and hyoid bone position. ${ }^{7}$ Mouth breathing habit which has high correlation with malocclusion due to lowered positioning of the tongue, impairing facial morphology during growth were excluded from this study.

The ages of the sample of the study taken were 1827 years, where the lymphoid tissue growth would have regressed and adult size of the hard and soft tissues would have attained. Airway dimensions are established in early childhood, beside airway becomes naturally less obstructive with increasing age with gradual natural compensation..$^{8,9}$

Lateral cephalograms in this study revealed smooth outline of the posterior pharyngeal wall without tonsillar hypertrophy and forward posturing of mandible associated with wider lower pharyngeal airway width. ${ }^{10}$

Descriptive statistic of five variables for gender revealed mean upper airway dimension as $11.40 \pm 1.84 \mathrm{~mm}$ and $11.68 \pm 1.96 \mathrm{~mm}$, lower airway dimension as $11.23 \pm 2.45 \mathrm{~mm}$ and $9.38 \pm 2.65 \mathrm{~mm}$, tongue height as $35.82 \pm 2.95 \mathrm{~mm}$ and $33.72 \pm 2.34 \mathrm{~mm}$, tongue length as $74.62 \pm 5.10 \mathrm{~mm}$ and $70.54 \pm 4.10 \mathrm{~mm}$, the position of hyoid bone as $10.93 \pm 4.14 \mathrm{~mm}$ and $9.12 \pm 4.53 \mathrm{~mm}$ respectively for male and female.

In contrast to the study by Allhaija ESA and Al-khateeb $\mathrm{SN},{ }^{1}$ this study revealed tongue size thicker and longer for male than females, lower airway dimension also larger than females. Greater dimension of the parameters in our study could be due to greater craniofacial dimension in males than females. However, hyoid bone was lowerly positioned in males than females similar to our study. Disproportionate increase in tongue mass relative to oral cavity may cause downward movement of tongue as one grows 
which plays a role in anterior and inferior movement of hyoid bone especially in males. ${ }^{11}$ Similar airway dimension in males and females has also been observed in study by Mislik B, et al. ${ }^{9}$ in spite of differences of craniofacial dimension in males and females.

According to McNamara upper pharyngeal width is 15$20 \mathrm{~mm}$ and lower pharyngeal width is $11-14 \mathrm{~mm}$, being greater than the observed value in our study. Ethnic diversity resulting in greater craniofacial structure could be the reason, since the sample population in McNamara is Caucasian. ${ }^{12}$

For generalisability pharyngeal airway dimension can be used as reference value to know airway patency and a width of two $\mathrm{mm}$ or less in this region may indicate airway impairment. Greater width of lower pharyngeal width may suggest habitual anterior positioning of the tongue or tonsillar enlargement. ${ }^{12}$ Regarding hyoid bone greater distance of hyoid bone from mandibular plane may be associated with sleep apnea. Recently it is considered as compensatory response rather than predisposing factor for airway obstruction. ${ }^{13}$

This study is the two dimensional study of three dimensional glosso-pharyngeal structure in lateral cephalogram where they are proven to be reproducible. ${ }^{5}$ Hence it is still widely used and further studies may be undertaken since it is routinely taken for orthodontic diagnosis. Beside, though this parameter has been put forward by McNamara in the past years, recently disordered breathing like sleep disordered breathing has reintroduced this parameter. ${ }^{12}$

\section{CONCLUSIONS}

Gender diversity regarding upper pharyngeal airway dimesnion was not observed in this study while other studies also revealed similarities in upper pharyngeal airway dimension between male and female, inspite of larger craniofacial dimension in males than females.

Lateral cephalograms taken routinely for orthodontic diagnosis could have additional parameter to evaluate airway dimension. We recommend further study of these parameters in hyperdivergent group with normal skeletal and dental relation.

\section{ACKNOWLEDGEMENTS}

The Authors would like acknowledge Prof. Amita Pradhan's valuable contribution in data analysis in this research work. We would also like to acknowledge the Department of Orthodontics, People's Dental College and Hospital, Kathmandu, Nepal for helping us to conduct this study.

\section{Conflict of Interest: None.}

\section{REFERENCES}

1. Abu Allhaija ES, Al-Khateeb SN. Uvulo-glosso-pharyngeal dimensions in different anteroposterior skeletal patterns. Angle Orthod. 2005 Nov;75(6):1012-8. [․ㅏbMed | Full Text I DOI]

2. Anandarajah S, Dudhia R, Sandham A, Sonnesen L. Risk factors for small pharyngeal airway dimensions in preorthodontic children: A three-dimensional study. Angle Orthod. 2017 Jan;87(1):138-46. [PubMed | DOI]

3. Celikoglu M, Buyukcavus MH. Changes in pharyngeal airway dimensions and hyoid bone position after maxillary protraction with different alternate rapid maxillary expansion and construction protocols: A prospective clinical study. Angle Orthod. 2017 Jul;87(4):519-25. [PubMed | Full Text $\mid \underline{\text { DOI] }}$

4. Nejaim Y, Aps JKM, Groppo FC, Haiter Neto F. Evaluation of pharyngeal space and its correlation with mandible and hyoid bone in patients with different skeletal classes and facial types. Am J Orthod Dentofacial Orthop. 2018 Jun;153(6):825-33. [PubMed | DOI]

5. da Costa ED, Roque-Torres GD, Brasil DM, Boscolo FN, de Almeida SM, Ambrosano GMB. Correlation between the position of hyoid bone and subregions of the pharyngeal airway space in lateral cephalometry and cone beam computed tomography. Angle Orthod. 2017 Sep;87(5):688-95. [PubMed | Full Text $\mid \underline{\text { DOI] }}$
6. Houston WJ. The analysis of errors in orthodontic measurements. Am J Orthod. 1983 May;83(5):382-90. [PubMed | DOI]

7. Moss ML. The functional matrix hypothesis revisited 2. The role of an osseous connected cellular network. Am J Orthod Dentofacial Orthop. 1997 Aug;112(2):221-6. [ubMed | Full Text $\mid \underline{D O I}]$

8. Preston CB, Tobias PV, Salem OH. Skeletal Age and Growth of the Nasopharynx in the Sagittal Plane: A Cephalometric Study. Semin Orthod. 2004 March;(10)1:16-38. [ Full Text | DOI]

9. Mislik B, Hänggi MP, Signorelli L, Peltomäki TA, Patcas R. Pharyngeal airway dimensions: a cephalometric, growth-study-based analysis of physiological variations in children aged 6-17. Eur J Orthod. 2014 Jun;36(3):331-9. [PubMed | Full Text | DOI]

10. Takemoto Y, Saitoh I, Iwasaki T, Inada E, Yamada C, Iwase $\mathrm{Y}$, et al. Pharyngeal airway in children with prognathism and normal occlusion. Angle Orthod. 2011 Jan;81(1):75-80. [PubMed | DOI]

11. Graber LW, Vanarsdall RL, Vig KWL, Huang GJ. Upper Airway cranial Morphology and Sleep Apnea. In: Orthodontics Current Principles and Techniques. 6th ed. St. Louis, Missouri: Elsevier; 2016. p 322-3. Available from: https://www.us.elsevierhealth.com/orthodontics- 


\section{1.html. [Full Text]}

12. Jacobson A. Radiographic cephalometry: From Basics to Video imaging. London, UK: Quintessence Publishing Co. Inc;1995. p113-124. Available from: https://books.google. co.in/books?id=4AZqAAAAMAAJ\&source=gbs_book_ other_versions. [Full Text]

13. Baik UB, Suzuki M, Ikeda K, Sugawara J, Mitani H.
Relationship between cephalometric characteristics and obstructive sites in obstructive sleep apnea syndrome. Angle Orthod. 2002 Apr;72(2):124-34. [uㅏMed | Full Text]

This work is licensed under a Creative Commons Attribution 4.0 International License. The images or other third party material in this article are included in the article's Creative Commons license, unless indicated otherwise in the credit line; if the material is not included under the Creative Commons license, users will need to obtain permission from the license holder to reproduce the material. To view a copy of this license, visit http://creativecommons.org/licenses/by/4.0/ 